\title{
Semi-stationary measurement as a tool to refine understanding of the soil temperature spatial variability
}

\author{
Michal Lehnert ${ }^{1 *}$, Miroslav Vysoudil ${ }^{2}$, and Petr Kladivo ${ }^{2}$ \\ ${ }^{1}$ Department of Physical Geography and Geoecology, University of Ostrava, Chittussiho 10, Ostrava, Czech Republic \\ ${ }^{2}$ Department of Geography, Faculty of Science, Palacký University, Olomouc, 17. listopadu 12, 77146 Olomouc, Czech Republic
}

Received December 6, 2014; accepted June 29, 2015

\begin{abstract}
A b s tra c t. Using data obtained by soil temperature measurement at stations in the Metropolitan Station Network in Olomouc, extensive semi-stationary measurement was implemented to study the spatial variability of the soil temperature. With the development of the research and computer technology, the study of the temperature is not limited by the complexity of the processes determining the soil temperature, but by the lack of spatial data. This study presents simple semi-stationary soil temperature measurement methods, which can contribute to the study of the spatial variability of soil temperature. By semi-stationary measurement, it is possible to determine the average soil temperature with high accuracy and the minimum soil temperature with sufficient accuracy at a depth of $20 \mathrm{~cm}$. It was proven that the spatial variability of the minimum soil temperature under grass at a depth of $20 \mathrm{~cm}$ can reach up to several degrees Celsius at the regional level, more than $1{ }^{\circ} \mathrm{C}$ at the local level, and tenths of ${ }^{\circ} \mathrm{C}$ at the sublocal level. Consequently, the standard stationary measurement of the soil temperature can be regarded as representative only for a very limited area. Semi-stationary soil temperature measurement is, therefore, an important tool for further development of soil temperature research.

K e y w o r d s: soil temperature, temperature measurement, field heterogeneity, soil moisture
\end{abstract}

\section{INTRODUCTION}

With the development of computer technology, which enabled previously impracticable complex approaches to soil temperature simulation to be applied, the interest in the study of the soil temperature is currently increasing. One can say it is a renaissance of the study of the soil temperature, which manifests itself in multicomponent physico-deterministic models such as TERRA LM (Heise et al., 2006), SHTM (Muerth, 2008), and NEST (Zhang et al., 2003, 2005). Therefore, the restricting factor is not the complexity of the process of determining the soil temperature, but the lack of representative spatial soil

*Corresponding author e-mail: michal.lehnert@gmail.com temperature data that would help to refine and validate the models. Installation of special stationary stations in sufficient density is expensive and, therefore, not feasible over a larger area. Moreover, it is often not representative of the area under study. The problem is the high spatial variability of the factors influencing the soil temperature, such as specific features of the local climate, the characteristics of the active surface, or the physical and hydric features of the soil. This fact also greatly limits the potential for the practical utilization of data from stationary measurements, especially those conducted at agrometeorological stations, in agriculture, forestry, ecology, and phenology, or civil engineering. As an alternative to stationary measurement, we propose a semi-stationary research approach.

Semi-stationary and expeditionary (one-time) measurement of the soil temperature is mentioned in WMO (2008) as one of the possible means of studying it. It is a standard research method used in meteorology, pedology, and geoecology (Minár et al., 2001; Vysoudil et al., 2012). Nevertheless, this approach to the study of the soil temperature is rarely used. Expeditionary measurement was used by Tang et al. (2011), who measured the soil temperature at 600 spots over a period of three days. However, they do not state when the temperature was measured or how it was standardized with regard to a specific point in time and the average temperature.

The aim of our study is to show a less commonly used approach to the study of the time-space variability of the soil temperature. The study was carried out in the vicinity of the city of Olomouc (Czech Republic). The purpose of the study is to show the possibilities and limits of semistationary and expeditionary soil temperature measurement and, therefore, initiate a proposal for standard methods for implementation thereof.

(C) 2015 Institute of Agrophysics, Polish Academy of Sciences 


\section{MATERIALS AND METHODS}

For a better idea about appropriate times for semistationary field measurements, we analyzed the soil temperature at a depth of $20 \mathrm{~cm}$ at five stations of the Metropolitan Station System in Olomouc (MESSO). The area of interest is located in a highly cultivated landscape on the boundary of a valley and a highland area in a temperate climatic zone in Central Europe (Fig. 1, Table 1). Chernosols and luvisols predominate in the lowland locations in the southwestern part of the area and fluvisols around the rivers. In



Fig. 1. Network of soil temperature measurement spots in Olomouc and its vicinity. the northeastern part of the highlands, the valleys mainly feature fluvisols, sometimes changing into gleysols. The peneplains contain cambisols.

The depth of $20 \mathrm{~cm}$ was chosen because it is phenologically important and still reflects the diurnal course of variations in the soil temperature, but the soil temperature at this depth does not react to very short fluctuations in the weather conditions. This depth is used at the majority of weather stations that measure the soil temperature and, therefore, it is used in a great number of papers (Bedrna, 1980; Bedrna and Gašparovič, 1986; Lehnert, 2012; Možný, 1991; Muerth, 2008; Rodskjer et al., 1989; Toogood et al., 1979; Valuš, 1974; Zhang et al., 2003). The soil temperature at the MESSO stations was measured by PT100-XM sensors with a precision of $0.15^{\circ} \mathrm{C}$ at tenminute intervals in the years 2010-2013. The active surface of every MESSO station was represented by a kept lawn.

During the experiment, we only selected radiation days without snow, because the daily variation in the soil temperature is best expressed on such days. A radiation day was a day when the cloud cover did not exceed more than twotenths (on average) and the average speed of the wind did not exceed $4 \mathrm{~m} \mathrm{~s}^{-1}$. In 2010-2013, 76 days met these criteria.

This data was used to detect appropriate time intervals for the semi-stationary measurement of the minimum and average diurnal soil temperatures at a depth of $20 \mathrm{~cm}$. If the temperature sensors move with the operators during the semi-stationary measurement, obtaining these intervals is crucial. The minimum and average diurnal temperatures were chosen because of their phonological importance.

To determine the appropriate interval for measuring the minimum diurnal temperatures, ten-minute data was used to establish the average hourly variability of the soil temperature (Fig. 2). At the same time, a time interval was set in which $95 \%$ of all the minimum temperatures start (Fig. 3). All the calculations were based on the time of the sunrise over the local meridian.

T a b l e 1. Characteristics of stationary MESSO stations with soil temperature measurements (2010-2013)

\begin{tabular}{|c|c|c|c|c|c|c|}
\hline Station & Latitude & Longitude & $\begin{array}{l}\text { Altitude } \\
\text { (m a.s.1.) }\end{array}$ & $\begin{array}{l}\text { Soil type } \\
\text { (WRB) }\end{array}$ & $\begin{array}{l}\text { Soil class } \\
\text { (USDA) } \\
(0-30 \mathrm{~cm})\end{array}$ & $\begin{array}{l}\text { Average annual } \\
\text { soil temperature } \\
\text { in } 20 \mathrm{~cm}\left({ }^{\circ} \mathrm{C}\right)\end{array}$ \\
\hline DDHL & $17^{\circ} 25^{\prime} 37.96^{\prime \prime}$ & $49^{\circ} 40^{\prime} 14.02^{\prime \prime}$ & 334 & Haplic Gleysol & sandy loam & 10.5 \\
\hline BYS & $17^{\circ} 11^{\prime} 15.68^{\prime \prime}$ & $49^{\circ} 32^{\prime} 33.29^{\prime \prime}$ & 234 & Luvic Chernozem & sandy clay loam & 10.4 \\
\hline KOPE & $17^{\circ} 20^{\prime} 19.8^{\prime \prime}$ & $49^{\circ} 37^{\prime} 38.6^{\prime \prime}$ & 362 & Stagnic Luvisol & sandy loam & 10.7 \\
\hline DOMI & $17^{\circ} 15^{\prime} 3.1^{\prime \prime}$ & $49^{\circ} 35^{\prime} 48.7^{\prime \prime}$ & 220 & Urbic Anthrosol & sandy loam & 11.2 \\
\hline BOT & $17^{\circ} 15^{\prime} 27.4^{\prime \prime}$ & $49^{\circ} 36^{\prime} 0.8^{\prime \prime}$ & 211 & Urbic Anthrosol & loam & 10.3 \\
\hline LETO & $17^{\circ} 12^{\prime} 33.8^{\prime \prime}$ & $49^{\circ} 35^{\prime} 30.9^{\prime \prime}$ & 258 & Urbic Anthrosol & loam & 10.6 \\
\hline
\end{tabular}




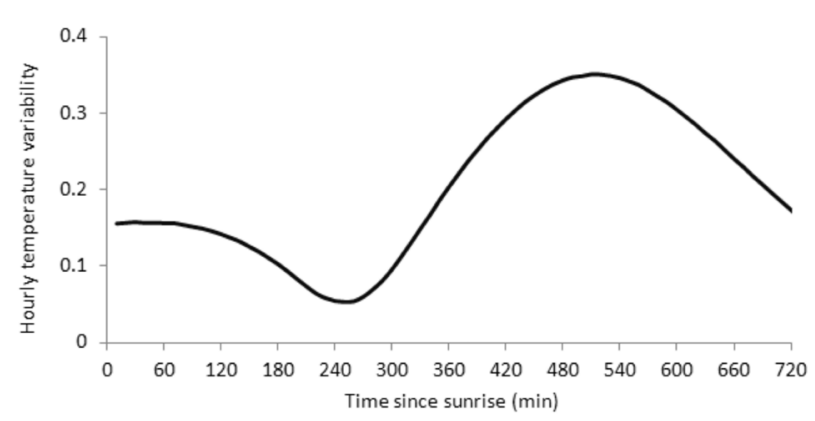

Fig. 2. Average hourly soil temperature variability at the stationary MESSO stations on radiation days in 2010-2013.



Fig. 3. Distribution of minimum soil temperature entrance at a depth of $20 \mathrm{~cm}$ based on the stationary MESSO stations on radiation days without snow in 2010-2013 (the interval of $95 \%$ of cases is marked by black dots).

Another method was used to determine the semi-stationary measurement intervals, which could be employed to calculate the average diurnal soil temperature. First of all, the average diurnal soil temperatures were calculated at each semi-stationary station using all 144 ten-minute-long measurement intervals of a given day. After that, the average diurnal temperatures $\left(T_{d}\right)$ were calculated according to a standard formula using three measurements:

$$
T_{\mathrm{d}}=\frac{t_{7}+t_{14}+t_{21}}{3}
$$

and also according to a modified variant of the standard formula where all three measurement terms were moved at ten-minute-long intervals before and after the standard time of reading:

$$
T_{\mathrm{d}}=\frac{t_{7( \pm \mathrm{x})}+t_{14( \pm \mathrm{x})}+t_{21( \pm \mathrm{x})} .}{3} .
$$

Subsequently, the absolute difference between the average temperatures calculated from all 144 figures and the average temperatures calculated using the standard and modified formulae was defined for each station. In the last phase, this number was averaged for all the stations (Fig. 4).

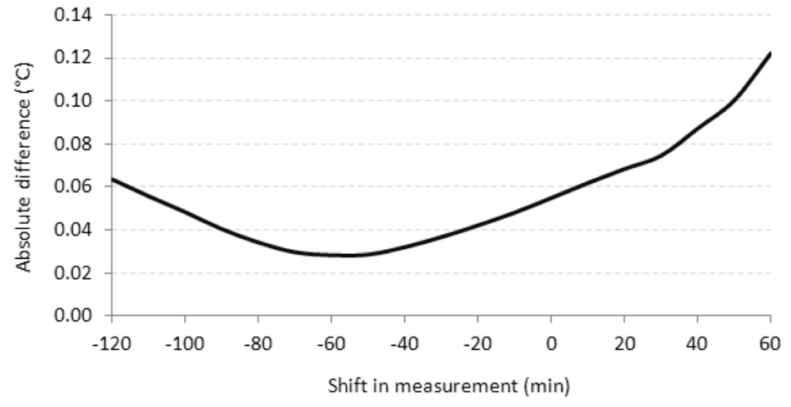

Fig. 4. Absolute difference between the average soil temperature determined from all diurnal measurements and the average soil temperature determined from three measurements conducted at various times shifted from the standard formula (Eq. (1)).

To determine the spatial variability of the minimum diurnal soil temperatures, semi-stationary measurements were performed in the area of interest at three spatial levels - micro (sub-local) (pedons), local (polypedons to pedotopes), and regional (pedochores). The measurements were performed with Hana HI 145 digital T-shaped thermometers with a maximum inaccuracy of $0.3^{\circ} \mathrm{C}$, which is in accordance with the WMO requirements (2008). During the measurements, the inertia of the thermometers was taken into consideration and the temperatures were read after the temperature stabilized on the sensor.

At first, in accordance with Minár et al. (2001), suitable research areas for regional semi-stationary measurement were selected in the area of interest using the leading factor method (relief - flatland, vegetation - grass). With expert selection, fifteen areas were selected which represented the research spots. The research spots never lay at the edge of the research area and they showed characteristic vegetation, soil moisture, and soil temperature during the preliminary research. The soil moisture was measured by means of Extech MO 750.

The soil temperature of the research spot was, as suggested by Buchan (2001), measured with two thermometers at once at least twice in order to obtain the most representative figure. Within the set time interval (Fig. 3), measurements on a regional scale were performed three times in total on these clear days: 26/4/2013, 18/6/2013, $15 / 8 / 2013$. The research spots were always visited in a different order. Therefore, any possible residual dependence between the measured temperature and the time of the measurement was minimised. Two semi-stationary spots were intentionally placed in the same area as the stationary stations with soil temperature measurement (BYST and DDHL). Therefore, the semi-stationary measurement could be standardized according to these stations. The metadata for the research spot with the semi-stationary soil temperature measurement are presented in Table 2. 


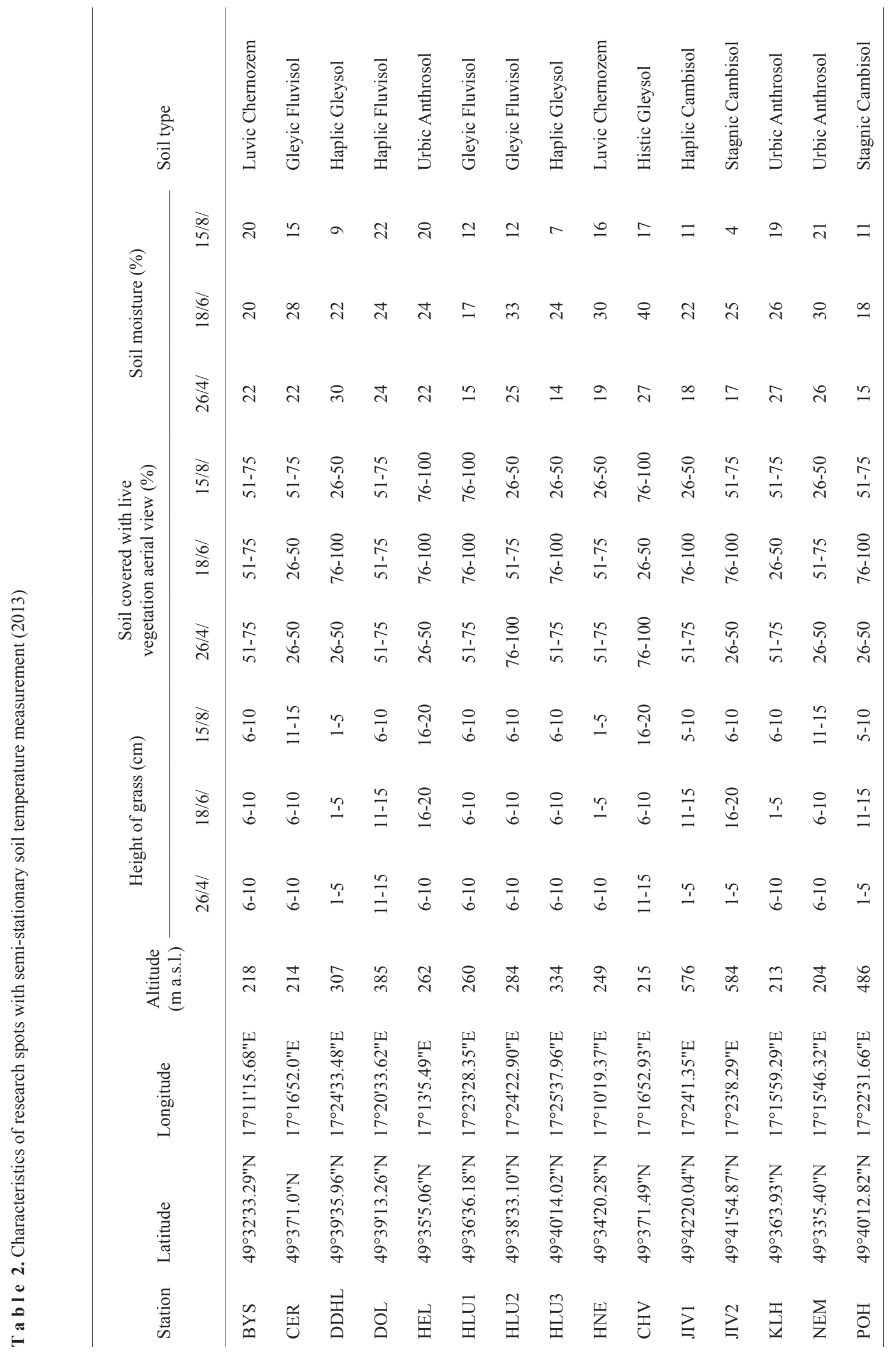


For the experimental semi-stationary soil temperature measurement at a local level, we selected the area with the research spot CER (CER $\sim \mathrm{C} 2$ ). This area was marked out with a square net of $75 \times 75 \mathrm{~m}$ with a side length of $25 \mathrm{~m}$. Approximately at the vertices of these squares, the soil temperature was measured (ie 16 research spots). Thermometers were again placed in spots with characteristic vegetation and soil moisture for the immediate vicinity (tens of centimetres). The measurements were conducted on three dates under the weather conditions described above: $14 / 3 / 2014,21 / 3 / 2014$, and 7/7/2014.

Semi-stationary measurement at a sub-local level was conducted using a square network of nine research spots, with the central research spot also being the research spot used for the local-level measurement $\left(\mathrm{C} 2 \sim \mathrm{C} 2_{\mathrm{b} 2}, \mathrm{D} 1 \sim \mathrm{D} 1_{\mathrm{b} 2}\right)$. The surroundings of spot $\mathrm{C} 2$ were chosen with regard to the continuity of the research - from the regional to the sublocal level - and the surroundings of spot D1 were chosen because the soil and vegetation in the area showed better signs of waterlogging when compared with other spots in the CER area. The thermometers were again placed in an area with characteristic features in its vicinity (units of centimetres).

\section{RESULTS}

The entrance figures of the minimum temperatures on days with clear weather without snow based on data from the stationary MESSO stations are spread around the median value $(282 \mathrm{~min}$ ) and standard deviation $(41 \mathrm{~min})$ - at the level of significance $p=0.05$, agreement with normal (Gaussian) distribution was successfully tested with an $\chi 2$ test. In $95 \%$ of cases, the minimum temperature comes about 202 to 363 min after sunrise (Fig. 3). The minimum hourly variability of the temperatures is logically in accordance with this interval (in $95 \%$ of cases, the inflection point of the diurnal soil temperature variation function lies within this interval). For this interval, the average hourly variability of the soil temperature at a depth of $20 \mathrm{~cm}$ is just $0.10^{\circ} \mathrm{C}$. Therefore, in $95 \%$ of cases, the maximum difference between 'the minimum temperature' measured at any time within this interval and the real minimum temperature reaches $0.27^{\circ} \mathrm{C}$ at most and, on average, only $0.14^{\circ} \mathrm{C}$.

On the basis of the analysis of the absolute difference in the average soil temperature and the soil temperature determined by three measurements, we discovered that, at least during radiation days, it is possible to precisely determine the average diurnal temperature using the averages of three values not only from the measurements at 7 a.m., 2 p.m., and 9 p.m., but also from the averages of terms that were moved at ten-minute-long intervals before and after the standard reading times. Therefore, the average temperature can be calculated from the three measurements moved by the same amount of time (up to $2 \mathrm{~h}$ earlier) with a $98 \%$ pos- sibility that the difference between the average of all the values and the average calculated from the three terms in this interval will not exceed $0.1^{\circ} \mathrm{C}$.

The minimum absolute difference between the average temperature calculated from all the diurnal measurements and the average temperature calculated from the three values was detected in cases in which the average temperature was determined at 6.10 a.m., 1.10 p.m. and 8.10 p.m. (Fig. 4) and not when calculated from the standard-time values, ie at 7 a.m., 2 p.m. and 9 p.m. The reasons might be the selection of radiation days, the specific soil quality in this region, and the location within the time zone. The key finding is the existence of an interval more than two hours long in which we can conduct the measurements necessary for the determination of the average soil temperature. This fact allows the realization of semi-stationary measurement during which the operator moves the sensor within the interval between the measuring spots without any fear of reducing the accuracy of the final average temperature as a result of the differences in the times at which the measurements were made in the particular areas.

The measurements conducted at 15 research spots in particular representative areas show high variability of the minimum soil temperatures at a regional level, even though we only measured temperatures on flat grass areas. Figure 5 shows that, especially at the beginning of the summer (in June) with a high proportion of clear radiation (net radiation), the differences between the minimum temperatures are as high as $6^{\circ} \mathrm{C}$. When comparing the minimum temperature values between the research spots, all three terms of measurement show similar interrelations. The spatial variability of the minimum temperatures is not coincidental. Therefore, we can prove a statistically important dependence of the minimum temperature on altitude (Fig. 6). After the categorization of the stations according to the soil moisture, or according to the vegetation index (categorization mitigates the stronger influence of altitude), we also described a statistically important dependence between the minimum soil temperature and the soil moisture (Fig. 7)

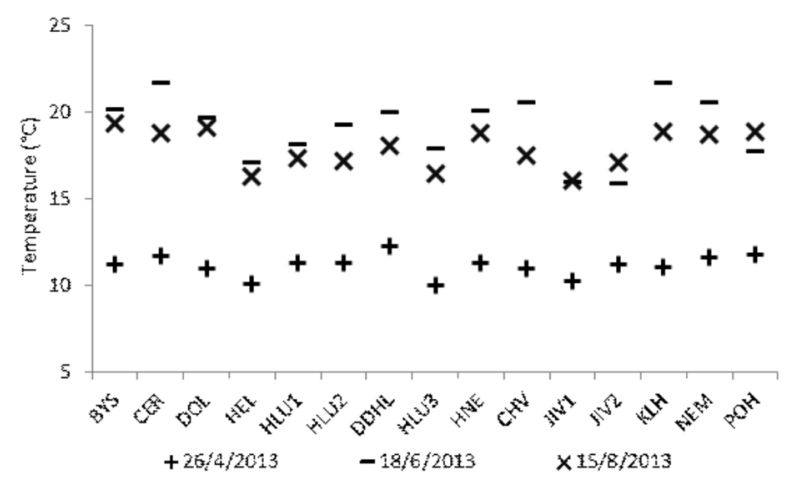

Fig. 5. Minimum soil temperature on selected radiation days based on semi-stationary measurements in Olomouc and its vicinity. 




Fig. 6. Relation of altitude to the difference in the average minimum diurnal soil temperature as an average of the minimum temperatures at all research points on a given day of measurement and the minimum soil temperature at a given research point on a given day of measurement.



Fig. 7. Relation of the difference in the average minimum diurnal soil temperature as an average of the minimum temperatures at all research points on a given day of measurement and the minimum soil temperature at a given research point on a given day of measurement towards the soil moisture after categorization of research points according to soil moisture.

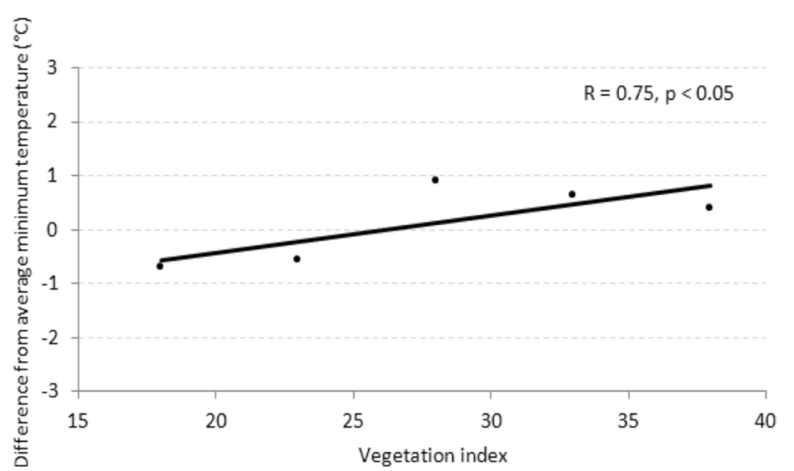

Fig. 8. Relation of the difference in the average minimum diurnal soil temperature as an average of the minimum temperatures at all research points on a given day of measurement and the minimum soil temperature at a given research point on a given day of measurement towards the vegetation index after categorization of research points according to the vegetation index. and between the minimum soil temperature and the vegetation index (Fig. 8). The vegetation index was determined as a product of the vegetation height and density indices. Vegetation height index formula: $1-5 \mathrm{~cm} \sim 1,6-10 \mathrm{~cm} \sim$ 2, $11-15 \mathrm{~cm} \sim 3,16-20 \mathrm{~cm} \sim 4 \mathrm{a}>20 \mathrm{~cm} \sim 5$; vegetation coverage index formula: $1-25 \% \sim 1,26-50 \% \sim 2,51-75 \% \sim$ $3,76-100 \% \sim 4$. As a result of the complexity and mutual interaction of the factors influencing the soil temperature, it is difficult to interpret all the aspects of the variability of the soil temperature.

Semi-stationary measurement was also conducted at a local level. The differences between the minimum soil temperatures at a local level are naturally smaller than at a regional level, because the factors influencing the soil temperature become quasi-homogenous. However, even in a quasi-homogenous area less than 1 ha in size, the minimum soil temperatures can differ by up to $1.5^{\circ} \mathrm{C}$ (Table 3 ). During the first, second, and third measurements, the formula for the spatial occurrence of minimum temperatures at a local level was different. The reasons were the changing height and density of the vegetation and soil moisture at the particular stations.

The results of the experimental measurements show that horizontal variability of the minimum soil temperature exists even at sub-local spatial level. In the experimental areas $\left(4 \mathrm{~m}^{2}\right)$ with their centre in spots where the soil temperature at a local level was measured $\left(\mathrm{C} 2 \sim \mathrm{C} 2_{\mathrm{b} 2}, \mathrm{D} 1 \sim \mathrm{D} 1_{\mathrm{b} 2}\right)$, we recorded differences of up to $0.4^{\circ} \mathrm{C}$. During the first,

T a b l e 3. Minimum soil temperatures $\left({ }^{\circ} \mathrm{C}\right)$ at a local level in research area CER

\begin{tabular}{|c|c|c|c|c|c|}
\hline \multirow{2}{*}{ Date } & \multirow{2}{*}{ Spot } & \multicolumn{4}{|c|}{ Vicinity of CER spot } \\
\hline & & A & B & $\mathrm{C}$ & D \\
\hline \multirow{4}{*}{$14 / 3 / 2014$} & 1 & 4.8 & 5.9 & 5.2 & 5.2 \\
\hline & 2 & 5.7 & 5.5 & 5.3 & 5.0 \\
\hline & 3 & 5.7 & 5.1 & 5.2 & 5.2 \\
\hline & 4 & 5.7 & 5.1 & 5 & 5.0 \\
\hline \multirow{4}{*}{$21 / 3 / 2014$} & 1 & 7.8 & 7.8 & 7.6 & 7.5 \\
\hline & 2 & 7.7 & 7.7 & 7.8 & 7.6 \\
\hline & 3 & 7.6 & 7.6 & 7.9 & 7.6 \\
\hline & 4 & 7.7 & 7.7 & 7.7 & 7.6 \\
\hline \multirow{4}{*}{ 7/7/2014 } & 1 & 19.1 & 19.1 & 19.3 & 18.1 \\
\hline & 2 & 18.8 & 18.7 & 19.1 & 19 \\
\hline & 3 & 19.3 & 18.9 & 19.1 & 19.6 \\
\hline & 4 & 18.9 & 19.6 & 19.6 & 19.1 \\
\hline
\end{tabular}

Vicitinity of CER spot - square grid with spacing of $25 \mathrm{~m}$. 
T a b I e 4. Minimum soil temperatures $\left({ }^{\circ} \mathrm{C}\right)$ at a sub-local level in research area CER

\begin{tabular}{lccccccc}
\hline \multirow{2}{*}{ Date } & & \multicolumn{3}{c}{ Vicinity of spot C2 } & \multicolumn{4}{c}{ Vicinity of spot D1 } \\
\cline { 3 - 8 } & \multirow{2}{*}{ Spot } & $\mathrm{a}$ & $\mathrm{b}$ & $\mathrm{c}$ & $\mathrm{a}$ & $\mathrm{b}$ & $\mathrm{c}$ \\
\hline \multirow{3}{*}{$14 / 3 / 2014$} & 2 & 5.4 & 5.3 & 5.4 & 5.2 & 5.2 & 5.3 \\
& 3 & 5.6 & 5.5 & 5.6 & 5 & 5.1 & 5.2 \\
& & & & & & & \\
$21 / 3 / 2014$ & 2 & 7.8 & 7.8 & 7.8 & 7.4 & 7.5 & 7.7 \\
& 3 & 7.7 & 7.9 & 8 & 7.5 & 7.6 & 7.6 \\
& 1 & 19.2 & 19.3 & 19.1 & 18.5 & 18.3 & 18.1 \\
$7 / 7 / 2014$ & 2 & 19 & 19.1 & 19.4 & 18.1 & 18.1 & 18.1 \\
& 3 & 19.2 & 19.4 & 19.4 & 18.1 & 18.3 & 18.2 \\
\hline
\end{tabular}

Vicinity of C2 and D1 spot - square grid with spacing of $1 \mathrm{~m}$.

second, and third measurements, the formula for the spatial occurrence of minimum temperatures at this level was also different (Table 4).

\section{DISCUSSION}

The accuracy of the determination of the minimum soil temperature at a depth of $20 \mathrm{~cm}$ based on semi-stationary measurement can be considered sufficient for a majority of practical applications (for example in agriculture or engineering). If it is not desirable to determine the measured temperature just as the rough minimum diurnal temperature, it is appropriate to measure the soil temperature at a certain time during the interval approximately 180 to $300 \mathrm{~min}$ after sunrise (for example at the midpoint of this interval). These measurements can serve as verification of the spatial representativeness of the data measured at a stationary research point, and, even better, they can help during the research that precedes the selection of the stationary measurement point. The average soil temperature determined by semi-stationary measurement is highly accurate and, therefore, it can also serve as an important source of data for the application and validation of models simulating the soil temperature and its regime.

On the basis of our experience, we propose the following method of semi-stationary measurement:

- determination of the time interval for semi-stationary measurement based on the depth of soil temperature measurement, the purpose, and local geographic conditions;

- selection of a representative spot for semi-stationary soil temperature measurement using preliminary research and the description of selected areas;
- assessment of soil temperature measurement frequency (according to the intended utilization of the results);

- repeated soil temperature measurement including description of the variable characteristics of the area (height and density of vegetation, soil moisture, and weather conditions);

- evaluation of the measurement according to the intended utilization.

During semi-stationary measurements, it is impossible, for practical reasons, to track the hard-to-measure metadata suggested for stationary measurement by Shein et al. (2009). Therefore, it is better to follow the instructions from WMO (2008), which recommends recording the slope inclination, character of the surface, and soil type. This data can be supplemented with the above-mentioned height and density of vegetation, soil moisture, and weather conditions. If it is possible, it is also good to add the amount of humus and granularity as important factors of thermic soil qualities (Abu-Hamdeh and Reeder, 2000; Tavman, 1996).

The above-mentioned relation between the soil temperature and altitude suggests that the decline in the minimum temperature with altitude does not have to be as smooth as Green and Harding $(1979,1980)$ describe for average temperatures. This is in accordance with the findings obtained by Elizbarashvili et al. (2007, 2010), who identified various degrees of a decline in the soil temperature with altitude for various soil types in Georgia. They state that the cause of this decline in the soil temperature is a higher wind velocity and, therefore, higher evaporation, higher amounts of precipitation, greater cloud cover, and the more frequent occurrence of local temperature inversions. These temperature inversions can disrupt the linear shape of the function of the decline in the minimum soil temperature with altitude. However, for more complex and convincing results, we need more measurements.

The influence of vegetation on the spatial variability of the minimum soil temperatures was also statistically proven at the regional level, but it is at its most profound at the local and sub-local levels. Therefore, our results confirm the findings (Coufal et al., 1993) that even weather stations with kept lawns do not represent the same conditions for soil temperature measurement because of the variations in the structure, height, and density of the lawn. Similar results concerning the influence of vegetation on the minimum temperature are presented by Oliver et al. (1987) and Sándor and Fodor (2012).

The influence of soil moisture on the minimum temperature has been physically clearly stated (de Vries, 1963; Yadav and Saxena, 1973). However, the empirical dependence is not so clear. This can be explained by the 'disruptive' influence of other factors interfering with the soil temperature, the non-linear character of the relation between thermal diffusivity and soil moisture, and its various processes for particular soil types (Ghumam and Lal, 
1985; Arkhangel'skaya and Umarova, 2008), and the complex mechanism of effective thermal conductivity caused by coupled heat and moisture transport (Johansen, 1977; Philip and de Vries, 1957; Thomas and He, 1995).

The described spatial variability of the soil temperature is a result of the combination and mutual interaction of the state of the atmosphere, character of the georelief and its surface, and quality of the soil environment. Regardless of the influence of the particular factors determining the spatial variability of the soil temperature, it is possible to claim that the spatial variability of minimum temperatures that has been discovered is in accordance with the findings of previous works. Shein et al. (2009) found out that there are differences in the soil temperature at a depth of $20 \mathrm{~cm}$ at the polypedon level (ie the local level) of up to $1^{\circ} \mathrm{C}$. This corresponds with our variability of minimum temperatures of up to $1.5^{\circ} \mathrm{C}$ at the local level. Buchan (1982) found out that diurnal soil temperatures at a depth of $10 \mathrm{~cm}$ can differ by up to $0.4^{\circ} \mathrm{C}$ over a horizontal distance of $\sim 10 \mathrm{~cm}$, nocturnal ones by up to $0.2^{\circ} \mathrm{C}$, and in the case of a one-time temperature deduction by up to $1.0^{\circ} \mathrm{C}$, which corresponds with our variability in soil temperature of up to $0.4^{\circ} \mathrm{C}$ over an area of $4 \mathrm{~m}^{2}$. In agreement with Shein et al. (2009), we can say that soil temperature measurement is only representative for a given pedon for the high accuracy requirements.

On the basis of these findings and the findings of other authors (Buchan, 1982; Coufal et al., 1993; Shein et al., 2009), it is clear that many standard stationary soil temperature measurements do not have to be representative for the given area, let alone for a larger region. Agrometeorological and weather stations, which usually provide soil temperature data, are often primarily located according to the principles of the measurement of basic meteorological factors. The hydrothermic regimes of the soil in the places where the measurements take place are, therefore, more or less coincidental. Considering this fact and the above-mentioned spatial variability, we can say that simple extrapolations and interpolations of the soil temperature for medium and small areas from a sparse network of stationary stations are entirely unrepresentative.

\section{CONCLUSIONS}

1. Even with a small number of devices and operators, semi-stationary soil temperature measurement conducted at time intervals delimited beforehand and at a depth of $20 \mathrm{~cm}$ enables the average diurnal soil temperature to be obtained with high accuracy and the minimum soil temperature with sufficient accuracy for a majority of practical purposes.

2. If the average diurnal soil temperature was determined from three readings, the highest accuracy was obtained when the averages were calculated from 6.10 a.m., 1.10 p.m., and 8.10 p.m. and not from the standard-time values, ie at 7 a.m., 2 p.m., and 9 p.m.
3. The spatial variability of the minimum soil temperature at a depth of $20 \mathrm{~cm}$ at the regional level can reach up to several degrees Celsius. At a local level, the minimum soil temperature can differ by more than $1{ }^{\circ} \mathrm{C}$ and, and at a sub-local level by tenths of ${ }^{\circ} \mathrm{C}$.

4. Soil temperature interpretations for medium and small areas based on simple extrapolation and interpolation methods from a sparse network of stationary stations are misleading.

5. The location of stationary thermal sensors should be preceded by repetitive research on the soil temperature.

6. It is necessary to study the factors influencing the spatial variability of the soil temperature because of their complex mutual relations, especially in a broader context.

7. Other, more detailed studies of the spatial variability of the soil temperature based on a dense network of measurement spots with standardized descriptions of metadata are necessary.

8. Semi-stationary soil temperature measurement should be an important method, which will help to develop the study of the spatial variability of the soil temperature.

\section{REFERENCES}

Abu-Hamdeh N.H. and Reeder R.C., 2000. Soil thermal conductivity effects of density, moisture, salt concentration, and organic matter. Soil Sci. Soc. America J., 64(4), 1285-1290.

Arkhangel'skaya T.A. and Umarova A.B., 2008. Thermal diffusivity and temperature regime of soils in large lysimeters of the experimental soil station of Moscow State University. Eurasian Soil Sci., 41(3), 276-285.

Bedrna Z., 1980. Subtypes of soil thermal regimes in Slovakia (in Slovak). Scientific Work VÚPVR, 10.

Bedrna Z. and Gašparovič J., 1986. Classification of soil temperature regime in Czechoslovakia (in Slovak). Geographical J., 38(1), 60-77.

Buchan G.D., 1982. Predicting bare soil temperature I. Theory and models for the multiday mean diurnal variation. J. Soil Sci., 33(2), 185-197.

Buchan G.D., 2001. Soil temperature regime. In: Soil and Environmental Analysis: Physical methods (Eds K.A. Smith, C.E. Mullins). Dekker Press, New York, USA.

Coufal V., Kott I., and Možný M., 1993. National climatic program of the Czech Republic: Soil temperature in winter half-year in the Czech Republic in the period of 1961-1991 (in Czech). CHMI, Prague, Czech Republic.

de Vries D.A., 1963. Thermal properties of soils. In: Physics of Plant Environment (Ed. W.R. Wijk). North Holland publishing Co., Amsterdam, Netherlands.

Elizbarashvili E.S., Elizbarashvili M.E., Maglakelidze R.V., Sulkhanishvili N.G., and Elizbarashvili S.E., 2007. Specific features of soil temperature regimes in Georgia. Eurasian Soil Sci., 40(7), 761-765.

Elizbarashvili E.S., Urushadze T.F., Elizbarashvili M.E., Elizbarashvili S.E., and Schaefer M.K., 2010. Temperature regime of some soil types in Georgia. Eurasian Soil Sci., 43(4), 427-435. 
Ghuman B.S. and Lal R., 1985. Thermal conductivity, thermal diffusivity, and thermal capacity of some Nigerian soils. Soil Sci., 139(1), 74-80.

Green F.H.V. and Harding R.J., 1979. The effects of altitude on soil temperature. Met. Mag., 108, 81-91.

Green F.H.V. and Harding R.J., 1980. Altitudinal gradients of soil temperatures in Europe. Trans. Inst. Br. Geog., New Series, 5, 243-254.

Heise E., Ritter B., and Schrodin R., 2006. Technical Report No. 9: Operational implementation of the multilayer soil model. Consortium for Small-Scale Modeling, Deutscher Wetterdienst, Offenbach am Main, Germany.

Johansen O., 1977. Thermal Conductivity of Soils. Cold Regions Research and Engineering Laboratory, Hanover, NH, USA.

Lehnert M., 2013. The soil temperature regime in the urban and suburban landscapes of Olomouc, Czech Republic. Moravian Geographical Reports, 21(3), 27-36.

Minár J., Barka I., Bonk R., Bizubová M., Čerňanský J., Falt’an V., Gašpárek J., Kolény M., Kožuch M., Kusendová D., Machová Z., Mičian L', Mičietová E., Michalka R., Novotný J., Ružek I., Švec P., Tremboš P., Trizna M., and Zat'ko M., 2001. Geoecological Research and Mapping in Large Scales (in Slovak). Geografika, Bratislava, Slovakia.

Možný M., 1991. The soil temperature regime in Czech hopgrowing region (in Czech). Meteorological Bulletin, 44(4), 115-120.

Muerth M., 2008. A Soil Temperature and Energy Balance Model for Integrated Assessment of Global Change Impacts at the Regional Scale. Ludwig-Maximilians-Universität München, Munich, Germany.

Oliver S.A., Oliver H.R., Wallace J.S., and Roberts A.M., 1987. Soil heat flux and temperature variation with vegetation, soil type and climate. Agric. Forest Meteorology, 39, 257-269.

Philip J.R. and de Vries D.A., 1957. Moisture movement materials under temperature gradients. Trans. Am. Geophysical Union, 38, 222-232.

Rodskjer N., Tuvesson M., and Wallsten K., 1989. Soil temperature during the growth period in winter wheat, spring barley and ley compared with that under a bare soil surface at Ultuna, Sweden. Swedish J. Agric. Res., 19(4), 193-202.
Sándor R. and Fodor N., 2012. Simulation of soil temperature dynamics with models using different concepts. The Scientific World J., ID 590287.

Shein E.V., Bannikov M.V., Troshina O.V., and Churkina O.A., 2009. Temperature field of complex soilscapes (by the example of the Vladimir opolie region). Eurasian Soil Sci., 42(2), 129-136.

Tang C.S., Shi B., Gao L., Daniels J.L., Jiang H.T., and Liu C., 2011. Urbanization effect on soil temperature in Nanjing, China. Energy Buildings, 43(11), 3090-3098.

Tavman I., 1996. Effective thermal conductivity of granular porous materials. Int. Communications in Heat and Mass Transfer, 23(2), 169-176.

Thomas H.R. and He Y., 1995. Analysis of coupled heat, moisture and air transfer in a deformable unsaturated soil. Geotechnique, 45(4), 677-689.

Toogood J.A., 1979. Comparison of soil temperatures under different vegetative covers at Edmonton. Canadian J. Soil Sci., 59(3), 329-335.

Valuš G., 1974. Soil temperature in Hurbanovo (in Slovak). Meteorological Bulletin, 27(3), 81-86.

Vysoudil M., Frajer J., Geletič J., Lehnert M., Lipina P., Pavelková Chmelová R., and Řepka M., 2012. The climate of Olomouc (in Czech). Palacký University, Olomouc, Czech Republic.

WMO, 2008. Guide to Meteorological Instruments and Methods of Observation. World Meteorological Organization, Geneva, Switzerland.

Yadav M.R. and Saxena G.S., 1973. Effect of compaction and moisture content on specific heat and thermal capacity of soils. J. Indian Soc. Soil Sci., 21(2), 129-132.

Zhang Y., Chen W., and Cihlar J., 2003. A process-based model for quantifying the impact of climate change on permafrost thermal regimes. J. Geophysical Res., Atmospheres, 108, (D22), ACL5.1-ACL5.16.

Zhang Y., Chen W., Smith S.L., Riseborough D.W., and Cihlar J., 2005. Soil temperature in Canada during the twentieth century: Complex responses to atmospheric climate change. J. Geophysical Res., Atmospheres, 110(D3).

Zhang Y., Wang S., Barr A.G., and Black T.A., 2008. Impact of snow cover on soil temperature and its simulation in a boreal aspen forest. Cold Regions Sci. Technol., 52(3), $355-370$. 